\title{
Véronique Dufief-Sanchez, Philosophie du roman personnel de Chateaubriand à Fromentin (1802-1863)
}

\section{Brigitte Louichon}

\section{(2) OpenEdition}

1 Journals

\section{Édition électronique}

URL : https://journals.openedition.org/studifrancesi/4717

DOI : 10.4000/studifrancesi.4717

ISSN : 2427-5856

Éditeur

Rosenberg \& Sellier

\section{Édition imprimée}

Date de publication : 1 avril 2012

Pagination : 158-159

ISSN : 0039-2944

\section{Référence électronique}

Brigitte Louichon, « Véronique Dufief-Sanchez, Philosophie du roman personnel de Chateaubriand à

Fromentin (1802-1863) », Studi Francesi [En ligne], 166 (I | LVI) | 2012, mis en ligne le 30 novembre 2015, consulté le 19 novembre 2021. URL : http://journals.openedition.org/studifrancesi/4717 ; DOI :

https://doi.org/10.4000/studifrancesi.4717

Ce document a été généré automatiquement le 19 novembre 2021.

\section{(c) 9 (i) $\Theta$}

Studi Francesi è distribuita con Licenza Creative Commons Attribuzione - Non commerciale - Non opere derivate 4.0 Internazionale. 


\title{
Véronique Dufief-Sanchez, Philosophie du roman personnel de Chateaubriand à Fromentin (1802-1863)
}

\author{
Brigitte Louichon
}

\section{RÉFÉRENCE}

VÉRONIQUE DUFIEF-SANCHEZ, Philosophie du roman personnel de Chateaubriand à Fromentin

(1802-1863), Genève, Droz, 2010, pp. 416.

1 Véronique Dufief-Sanchez s'intéresse au rôle que joue la fiction dans nos représentations du réel à partir (ou au moyen) d'un ensemble de romans du XIX siècle, qu'elle regroupe sous la notion de «roman personnel». La première partie de l'ouvrage vise à justifier l'intérêt de l'usage de cette catégorie générique puis à la définir précisément.

2 Depuis la thèse de Joachim Merlant (1905, réed. 1978), cette notion est assez peu fréquemment utilisée et, en général, comme synonyme de «roman autobiographique», lequel est indissociable d'une critique dont l'objectif relève du décryptage biographique. V. Dufief-Sanchez propose un historique permettant de comprendre l'émergence du genre au début du XIx ${ }^{e}$ siècle puis une «actualité du roman personnel». Avouons que ces quelques pages sont un peu déroutantes puisque, d'une part, «la définition du genre et du corpus» ne vient qu'ensuite et que, d'autre part, l'historique convoque des œuvres tandis que la réflexion sur l'actualité du genre renvoie à l'outillage conceptuel.

3 Les pages suivantes clarifient les choses grâce au retour à Sainte-Beuve, à la présentation du corpus, à l'énonciation de critères et à l'étude des limites du genre. C'est un genre bref, sérieux, écrit à la première personne, dans lequel l'auteur peut sans difficulté être identifié au personnage principal (entre autres grâce au paratexte). Cependant (et c'est en cela que le propos de l'auteure est stimulant), le moi de l'auteur 
éclate dans tous les personnages avec lesquels le sujet fictionnel est en relation. C'est dans cette logique que l'on peut comprendre les dispositifs de confessions fictives souvent utilisés par les romanciers. Au cœur du récit, se trouvent donc le désir de savoir et le désir de se connaître.

4 Le roman personnel est «une formule possible des différentes combinaisons imaginables entre autobiographie et fiction» (p. 51), lié au romantisme envisagé comme conception du monde et interrogé par les «romanciers personnels», c'est une réflexion concrète sur les vertus philosophiques de la fiction.

5 À partir de ce cadre, l'auteure propose, dans la suite de l'ouvrage, des lectures souvent stimulantes de chacune des œuvres constituant le corpus. Ces lectures sont organisée en trois parties: les «initiateurs» (René, Obermann, Adolphe, Volupté), les épigones du second rang» (Émile d'Émile de Girardin, Aloys de Custine, Arthur d'Eugène Sue, Voyage autour de mon jardin d'Alphonse Karr, Mémoire d'un suicidé de Du Camp) et «les romans de l'écrivain» (La Confession d'un enfant du siècle, Le Lys dans la vallée, Les Mémoires d'un fou, Novembre, Raphaël et Dominique). Ce regroupement permet de construire une sorte de continuum historique entre des œuvres assez dissemblables sur de nombreux aspects, même si la confession ou l'autobiographie fictive constituent tout ou partie des romans. On peut sans doute discuter ce regroupement et même cette construction générique. Mais cela importe peu. Ce qui est précieux, c'est la mise en évidence de la confiance accordée par des romanciers si différents à la force de la fiction.

Le propos général de l'ouvrage entre en résonance profonde avec des questionnements très actuels autour des enjeux des humanités, de la littérature et de la fiction (cfr. Yves CITTON, L'Avenir des humanités; Vincent Jouve, Pourquoi étudier la littérature?; Jean-Marie SCHAEFFER, Petite écologie des études littéraires: pourquoi et comment étudier la littérature?). Notre époque met l'accent sur la dimension heuristique de la fiction. Valérie DufiefSanchez montre que les romanciers personnels du XIX siècle, en créant des personnages fictionnels et fictifs pris dans une forme subjective, en ont expérimenté les pouvoirs. 